\title{
THE THIRD ANODIC HYDROGEN PEAK ON PLATINUM; SUBSURFACE $\mathrm{H}_{2}$ ADSORPTION
}

\author{
T. Frelink, ${ }^{*}$ W. Visscher and J. A. R. van Veen \\ Laboratory for Inorganic Chemistry and Catalysis, Eindhoven University of Technology, P.O. Box 513, \\ 5600 MB Eindhoven, The Netherlands
}

(Received 28 June 1994; in revised form 6 December 1994)

\begin{abstract}
The occurrence of the third anodic hydrogen peak was investigated on platinized platinum. Using DEMS in combination with Cyclic Voltammetry it is shown that adsorbed molecular hydrogen is the cause of this third peak. It is suggested that this hydrogen is presented in a subsurface state of $\mathrm{Pt}$ since disturbance of the Pt surface structure by oxide formation is necessary for the third peak to appear.
\end{abstract}

Key words: platinum, DEMS, third anodic hydrogen peak, subsurface hydrogen.

\section{INTRODUCTION}

The electrochemical adsorption of hydrogen on $\mathrm{Pt}$ in acid electrolytes has long been a major subject of investigations[1-3]. The early research on this subject has been excellently reviewed by Woods[4]. It is shown that on polycrystalline platinum and platinized platinum, multiple adsorption states are possible. These different adsorption states were ascribed by Will[5] to adsorption on different crystal planes ((100), (110) and (111)). This idea has been generally accepted since then, though the assignment of the peaks to the different crystal plancs has becn changing throughout the years. It seems to be well established now that strongly bonded hydrogen $\left(\mathrm{H}_{\mathrm{s}}\right.$, $E_{\mathrm{p}}=+0.28 \mathrm{~V}$ vs. $\mathrm{RHE}$ ) is due to adsorption on the $\mathrm{Pt}(100)$ plane. Weakly bonded hydrogen $\left(\mathrm{H}_{\mathrm{w}}, E_{\mathrm{p}}=\right.$ $+0.12 \mathrm{~V}$ vs. $\mathrm{RHE}$ ) has been assigned to both the $\mathrm{Pt}(110)$ and the $\operatorname{Pt}(111)$ plane $[6,7]$. Often also a socalled third anodic hydrogen peak $\left(\mathrm{H}_{3 \mathrm{rd}}\right)$, is observed at a potential between the strongly and weakly bonded hydrogen peaks. There has been much discussion on the origin of this peak because it only appears in the anodic part of the cyclic voltammogram and not in the cathodic part; furthermore at high sweep rates, it is not observed at all[8]. This peak was assigned by Will[5] to $\mathrm{H}$ adsorption on $\mathrm{Pt}(111)$ sites. From measurements at platinized platinum Kinoshita et al.[7] concluded that the amount of third anodic hydrogen depends on the amount of edge and vertex atoms. The fact that the third peak only appears when low sweep rates are used combined with the condition that the potential scan must be taken to potentials below $+0.13 \mathrm{~V}$, led Breiter and others to the conclusion that it is due to hydrogen absorption[9-11]. Kinoshita et al.[12], however, calculated that hydrogen absorption cannot be responsible for the third anodic hydrogen

* Author to whom correspondence should be addressed. peak because hydrogen only dissolves in $\mathrm{Pt}$ in very small amounts. Stonehart[13] found that the third peak grows with time when the potential is held at a value below $+0.12 \mathrm{~V}$ and suggested that the peak might be due to surface diffusion and reorientation of adsorbed hydrogen thus forming a $\mathrm{H}_{3}^{+}$species. Tegtmeyer et al.[14] showed with DEMS that $\mathrm{H}_{2}$ formation is indeed possible below $+0.12 \mathrm{~V}$. It was observed by Loo and Furtak[6] that the third peak disappears if the anodic sweep is reversed at potentials in the double layer region while the strongly and weakly bonded hydrogen peaks grow in intensity. If the reverse potential is then increased to the oxide formation region, the third peak reappears. It was suggested that certain active sites have to be formed capable of sorbing the hydrogen species of the third peak. Gomez and Clavilier[15] showed that $\mathrm{Pt}(110)$ behaves similarly to the polycrystalline $\mathrm{Pt}$ : the third peak is clearly present in the cyclic voltammogram of the single crystal after one oxidationreduction cycle between 0 and $+1.2 \mathrm{~V}$ vs. RHE. It is argued that $\mathrm{Pt}(110)$ sites are necessary for the third anodic hydrogen peak to appear. Recently Sumino and Shibata[16] confirmed the Stonehart results and concluded that it is very plausible that upd $\mathrm{H}_{2}$ is responsible for the third peak. This hydrogen molecule is supposed to be occluded into the surface layer reconstructed during the anodic cycle. Upon conditioning at low potentials, not only the third peak increases with time, but also the amount of weakly adsorbed hydrogen decreases. It follows from the change in $\mathrm{H}_{3 \mathrm{rd}} / \mathrm{H}_{\mathrm{w}}$ that twice as many electrons must be involved in the process responsible for the third hydrogen neak, when compared to the weakly adsorbed hydrogen.

Until now most studies have been dealing with smooth Pt. To seek further evidence for the assignment of the third peak to ad- or absorbed $\mathrm{H}_{2}$, and thus substantiate the results of Sumino and Shibata[16], we performed experiments with platinized $\mathrm{Pt}$. 


\section{EXPERIMENTAL}

All measurements were performed in a conventional three electrode cell, with a $\mathrm{Hg} / \mathrm{Hg}_{2} \mathrm{SO}_{4}$ (MSE $E=+0.65 \mathrm{~V}$ vs. RHE) reference electrode and a platinum sheet as a counter electrode. All potentials are referred to the RHE. The working electrode was a Pt $\left(\right.$ area $\left.=4 \mathrm{~cm}^{2}\right)$ sheet which was platinized galvanostatically with a current density of $10 \mathrm{~mA} \mathrm{~cm}^{-2}$ for $10 \mathrm{~min}$. Roughness factors, calculated from hydrogen desorption in a cyclic voltammetric experiment and assuming that $1 \mathrm{~cm}^{2}$ corresponds with $210 \mu \mathrm{C}$, ranged from 200 to 300 . For the Differential Electrochemical Mass Spectroscopy (DEMS) measurements a platinized Pt gauze was used. All currents in the cyclic voltammetric measurements are given with respect to the real surface areas of the electrodes, taking into account the roughness factor. Measurements were carried out in $0.5 \mathrm{M} \mathrm{H}_{2} \mathrm{SO}_{4}$ as a supporting electrolyte, which was prepared from ultrapure acid (Merck) and ultrapure (18.2 M $)$ water (Elgastat). The cyclic voltammetric measurements were performed with a computer controlled Autolab Potentiostat (Eco Chemie) or a Wenking POS 73 potentioscan. The setup of the DEMS is similar to those described before[7].

\section{RESULTS AND DISCUSSION}

The platinized electrode gives a cyclic voltammogram as is shown in Fig. 1, the potential limits are 0 and $+1.3 \mathrm{~V}$. When compared to the literature data on single crystal electrodes, the following results are obtained: The anodic peak at $+0.10 \mathrm{~V}$, due to weakly bonded hydrogen, is close to the potential which is given in literature for the hydrogen adsorption on a Pt(110) surface[18-20]. The peak at $+0.23 \mathrm{~V}$, due to the strongly bonded hydrogen, is close to the values given by Yamamoto[20] (scanrate, $v=50 \mathrm{mV} / \mathrm{s})$ and Santos $[21](v=50 \mathrm{mV} /$ s) for $\mathrm{Pt}(100)$, but $100 \mathrm{mV}$ lower than the values reported in [18] $(v=50 \mathrm{mV} / \mathrm{s})$ and [19] (v not specified). Rodes et al.[22] showed that this difference is due to the presence of surface defects introduced during the pretreatment.

By varying the scan rate, slight changes in the peak potentials are noticed. In Fig. 2 the peak poten-

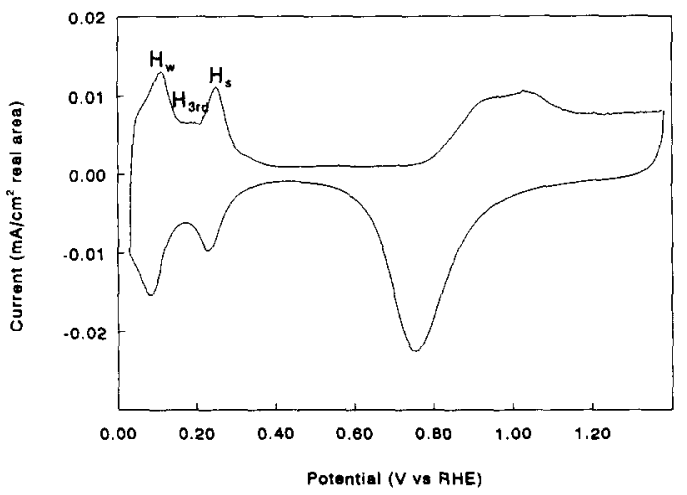

Fig. 1. Cyclic voltammogram of platinized platinum. $0.5 \mathrm{M}$ $\mathrm{H}_{2} \mathrm{SO}_{4}, v=10 \mathrm{mV} / \mathrm{s}$.

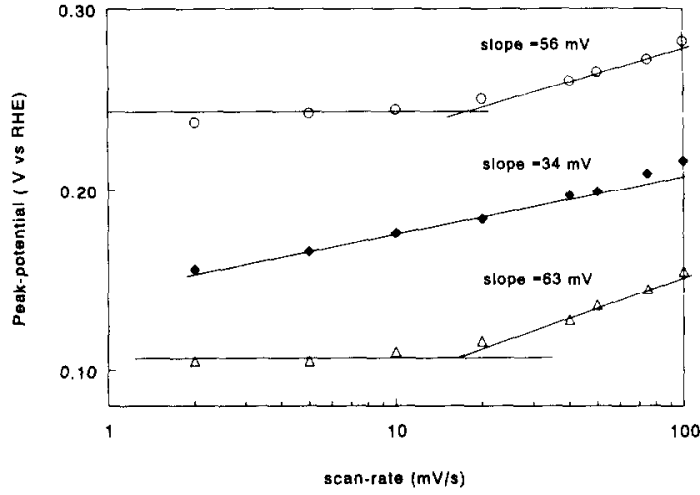

Fig. 2. Peak-potential as a function of the scan-rate for the three hydrogen desorption peaks on platinized platinum. $(O): \mathrm{H}_{s} ;(\diamond): \mathrm{H}_{3 \mathrm{rd}} ;(\Delta): \mathrm{H}_{w} \cdot 0.5 \mathrm{M} \mathrm{H}_{2} \mathrm{SO}_{4}$

tial of the three different peaks are plotted against $v$. The figure shows that the kinetic behavior of the third desorption process is substantially different from that of the other two. The peaks due to strongly and weakly bonded hydrogen are reversible at low scan rates and start to show irreversible behavior at scan rates above $20 \mathrm{mV} / \mathrm{s}$. This result is in agreement with earlier findings at polycrystalline $\mathrm{Pt}[3]$, but differs from the results of Sumino et al. [16] who found that both peaks are reversible up to $10 \mathrm{~V} / \mathrm{s}$. The third peak shows irreversible behavior even at low scan rates, and the slope of this line is approximately half of that for the other two peaks, and so these results might indicate that a different mechanism is responsible for the third peak. In order to check whether this is due to local $\mathrm{pH}$ changes caused by the roughness of the platinized $\mathrm{Pt}$, we repeated the same experiments with smooth Pt. The change of the three hydrogen peaks with scan rate was similar to that for the platinized Pt. We can therefore conclude that the potential shift of the three hydrogen peaks as a function of the scan rate is not due to the roughness of the electrode.

In order to find out how the initial potential influences the third anodic peak, we fixed the potential between 0 and $+0.12 \mathrm{~V}$ for different times before starting the anodic scan, these values are below the peak-potential of $H_{w}$. The results are given in Figs 3 and 4. In Fig. 3 it is shown that if the potential is fixed for 100 seconds at values below $+0.08 \mathrm{~V}$, the third anodic hydrogen peak increases, while if the fixed potential is at $+0.08 \mathrm{~V}$ or higher, no increase in the third hydrogen peak is found.

Figure 4 shows the results for different conditioning times at $+0.07 \mathrm{~V}$ vs. RHE (after which an anodic scan was started at $+0.03 \mathrm{~V}$ ) in $\mathrm{H}_{2} \mathrm{SO}_{4}$. An increase in the third-peak current is found with an increase in conditioning time up to 100 seconds; at values higher than 100 seconds no further increase was seen.

As mentioned in the introduction, these results can be explained by assuming that $\mathrm{H}_{2}$ is already formed at these potentials. To verify whether this is indeed so, we performed DEMS experiments under the same conditions as well as under steady state conditions. The results are shown in Fig. 5. It is seen that during the cathodic scan $\mathrm{H}_{2}$ is detected at potentials 


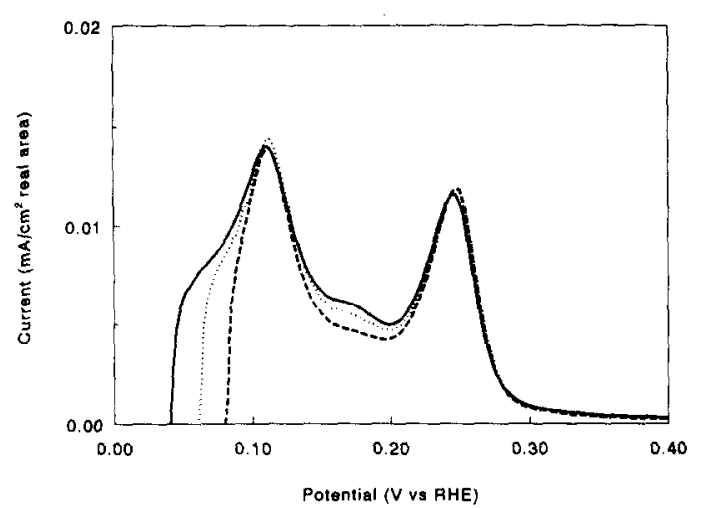

Fig. 3. Hydrogen desorption on platinized $\mathrm{Pt}$ after holding the potential for $t=100 \mathrm{~s},(\longrightarrow) \mathrm{E}_{\text {hold }}=+0.03 \mathrm{~V} ;(\cdots)$ $\mathrm{E}_{\text {hold }}=+0.06 \mathrm{~V} ;(--) \mathrm{E}_{\text {hold }}=+0.08 \mathrm{~V} .0 .5 \mathrm{M} \mathrm{H} \mathrm{SO}_{4}$, $v=10 \mathrm{mV} / \mathrm{s}$.

of $c a .+0.08 \mathrm{~V}$ and lower. The same holds for the anodic scan.

Further evidence for this was sought for by an expcriment in which we adsorbed and oxidized

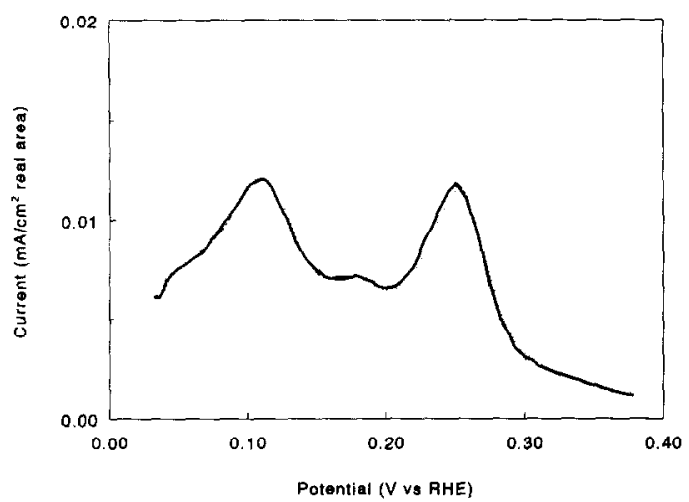

Fig. 4. Hydrogen desorption after holding the potential at $\mathrm{E}=+0.03 \mathrm{~V}$ for different times: $(\cdots) t=0 \mathrm{~s} ;(---)$ $t=40 \mathrm{~s} ;(\longrightarrow) t=60 \mathrm{~s} .0 .5 \mathrm{M} \mathrm{H}_{2} \mathrm{SO}_{4}, v=10 \mathrm{mV} / \mathrm{s}$.

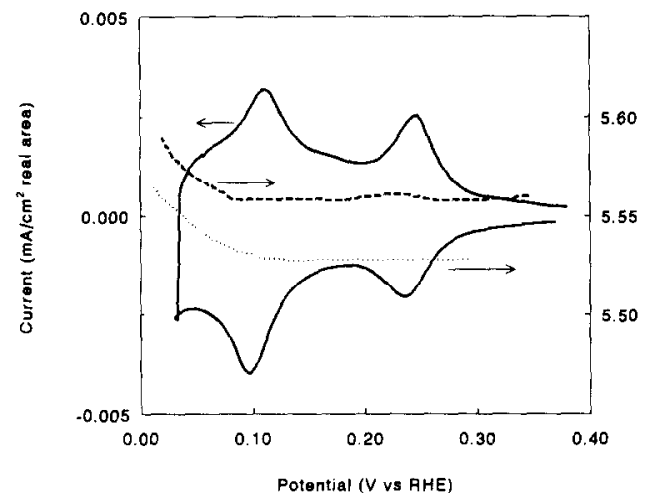

Fig. 5. Hydrogen adsorption-desorption area together with the change in the amount of hydrogen detected by the mass-spectrometer. The mass-signal is only shown for the cathodic scan; $(\cdots)$ change in $\mathbf{H}_{2}$ signal during a steady state measurement; $(-\ldots)$ change in $\mathrm{H}_{2}$ signal during a cyclic voltammetric measurement $(v=2 \mathrm{mV} / \mathrm{s}) . \quad 0.5 \mathrm{M}$ $\mathrm{H}_{2} \mathrm{SO}_{4}$. gaseous molecular hydrogen. This was done by bubbling a mixture of hydrogen/argon through the electrolyte for 40 seconds, followed by bubbling with pure argon to remove the hydrogen from the solution, while the potential was fixed at $+0.08 \mathrm{~V}$. In the following anodic scan a large increase in the third peak is observed, while almost no increase is found for the other two peaks (Fig. 6). It is thus evident that molecular hydrogen is responsible for the third peak. Because only the third hydrogen peak increases, oxidation of gaseous molecular hydrogen can be excluded.

Remains the question why the occurrence of the third peak is subject to potential cycling to potentials in the oxide region. To explore this further we carried out combined cyclic voltammetric and DEMS experiments in which we varied the upper potential limit. Figure $7 a$ and $b$ show that when the anodic reverse potential is lowered, the height of the third peak decreases. At potentials where no oxide formation takes place, the third anodic hydrogen peak can not be detected. This result is in agreement with that of Clavilier et al.[15] on $\mathrm{Pt}(110)$ and Loo[6]. In Fig. 8 a correlation is given between the peak current of $\mathrm{H}_{3 \mathrm{rd}}$ and the percentage of the surface that is oxidized. The latter is calculated by taking the ratio between the oxide reduction charge and the oxide reduction charge of a full scan to $+1.3 \mathrm{~V}$. The linear relationship strongly suggests that the number of oxidized sites is directly related to the amount of $\mathrm{H}_{3 \mathrm{rd}}$. It furthermore appears, $c f$. Fig. $7 b$, that the $\mathrm{H}_{2}$ evolution commences at a lower potential on a non-oxidized surface. This is consistent with results[23] on hydrogen evolution which show that a different mechanism prevails when the $\mathrm{Pt}$ surface is oxidized before hydrogen is cvolved.

The oxygen adsorption-desorption appears to be responsible for the formation of sites on which the species of the third anodic hydrogen peak may be formed. This may be related to the formation of (110) sites with surface structures, which sites were shown to be responsible for the appearance of the third peak [15] on the single crystal electrode. The process responsible for the formation of the third peak is a slow one (vide infra) and the species concerned in this process can therefore not be a hydrogen atom

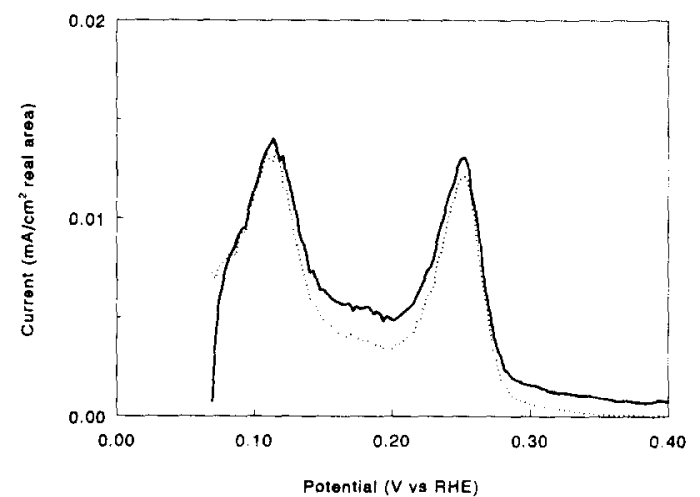

Fig. 6. Hydrogen desorption after adsorbing $\mathrm{H}_{2}$ gas for $t=40 \mathrm{~s}$ at $\mathrm{E}_{\mathrm{ad}}=+0.08 \mathrm{~V}$. Before starting the anodic scan electrolyte was flushed with argon to remove the bulk hydrogen gas. $0.5 \mathrm{M} \mathrm{H}_{2} \mathrm{SO}_{4}, v=10 \mathrm{mV} / \mathrm{s}$. 

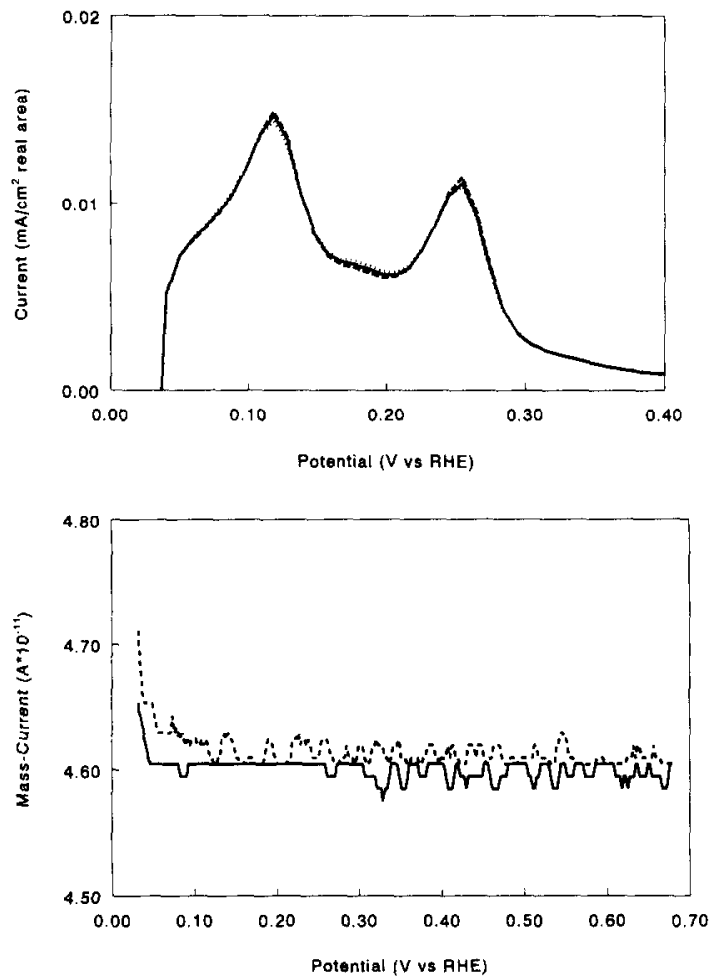

Fig. 7. Hydrogen desorption for cyclic voltammograms with different anodic scan limits. (a) Current-potential curve: $(\cdots) \mathrm{E}_{\text {anod }}=+1.28 \mathrm{~V} ;\left(\longrightarrow \mathrm{E}_{\text {anod }}=+1.08 \mathrm{~V}\right.$; $(--) \mathrm{E}_{\text {anod }}=+0.78 \mathrm{~V}$. (b) Mass-potential curve: $(\square)$ $\mathrm{E}_{\mathrm{anad}}=+0.78 \mathrm{~V} ;(---) \mathrm{E}_{\text {anod }}=+1.28 \mathrm{~V} .0 .5 \mathrm{M} \mathrm{H}_{2} \mathrm{SO}_{4}$, $v=10 \mathrm{mV} / \mathrm{s}$.

adsorbing on the surface. Furthermore, since the appearance of the third peak is closely related to the start of the hydrogen evolution, we suggest that adsorbed molecular hydrogen (which may well be the intermediate in the hydrogen evolution) is the species oxidized in the third anodic peak. To account for the slowness of the process, we suggest that the molecular hydrogen is sub-surface adsorbed and forms possibly on (110) sites with surface structures, generated by oxidation-reduction cycles. The fact

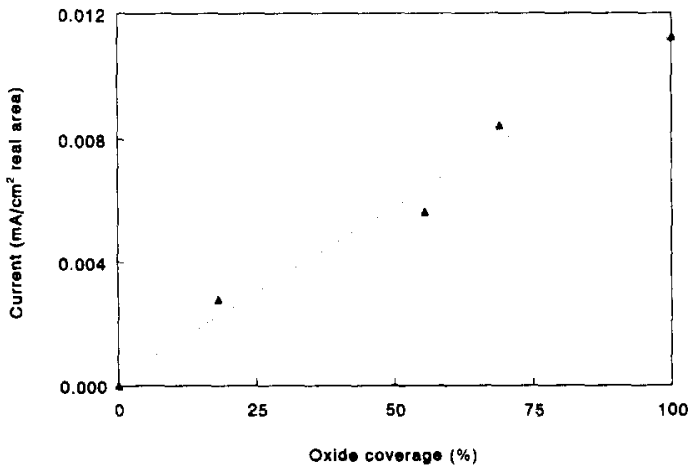

Fig. 8. Current of the third anodic hydrogen peak as a function of the amount of surface oxide coverage. The current is measured with respect to the value of the nonoxidized surface. that the current for the third anodic hydrogen peak is limited, must then be due to the limited amount of $\mathrm{Pt}(110)$ sites with surface structures that can be formed on a platinized $\mathrm{Pt}$ surface.

\section{CONCLUSIONS}

In this work we confirmed the previous results of Sumino[16] and Loo[6] for Pt on the third anodic hydrogen peak on platinized Pt. By in-situ monitoring with DEMS we further gathered additional evidence for the hypothesis that $\mathrm{H}_{2}$ is responsible for the third peak. These measurements showed that $\mathrm{H}_{2}$ evolution occurs at potentials below $+0.10 \mathrm{~V}$ and that this is retarded on those surfaces on which no third anodic hydrogen peak occurs. The fact that $\mathrm{H}_{2}$ adsorbed from the gas phase, shows similar behavior as electrochemically generated $\mathrm{H}_{2}$, makes it very unlikely that the $\mathrm{H}_{2}$ species is absorbed in the bulk of the electrode. The sites, where the $\mathrm{H}_{2}$ species is formed, have to be created via oxidation of the surface and it is well known that this oxidation involves a place exchange. This probably involves formation of $\mathrm{Pt}(110)$ sites with surface structures. This in combination with the fact that the process responsible for the third peak is found to be slow, leads us to the conclusion that the third hydrogen species is sub-surface molecular hydrogen.

\section{REFERENCES}

1. F. G. Will and C. A. Knorr, Z. Elektrochem. 64, 258 (1960).

2. F. G. Will and C. A. Knorr, Z. Electrochem. 64, 270 (1960).

3. B. E. Conway and II. Angerstein-Kozlowska, Acc. Chem. Res. 14, 49 (1981).

4. R. A. Woods, Chemisorption at electrodes in Electroanalytical Chemistry, Vol. 9 (Edited by A. J. Bard). Marcel Dekker Inc., New York (1976).

5. F. G. Will, J. Electrochem. Soc. 112, 451 (1965).

6. B. H. Loo and T. E. Furtak, Electrochim. Acta 25, 505 (1980).

7. K. Kinoshita and P. Stonehart, Electrochim. Acta 20, 101 (1975).

8. V. S. Bagotzky, Yu. B. Vassiliev and I. I. Pyshnograeva, Electrochim. Acta 16, 2141 (1971).

9. R. P. Petukhova, I. I. Astakhov and B. I. Podlovchenko, Elektrakhim. 7, 1498 (1971).

10. T. Biegler, Aust. J. Chem. 27, 2571, 2587 (1973).

11. M. W. Bretier, Electrochemical Processes in Fuel Cells. Springer Veriag, New York (1969).

12. K. Kinoshita, J. Lindquist and P. Stonehart, J. Cat. 31, 325 (1973).

13. P. Stonehart, Electrochim. Acta 15, 1853 (1970).

14. D. Tegtmeyer, A. Heindrichs and J. Heitbaum, Ber. Bunsenges, Phys. Chem. 93, 201 (1989).

15. R. Gomez and J. Clavilier, J. Electroanal. Chem. 354, 189 (1993).

16. M. P. Sumino and S. Shibata, Electrochim. Acta 37, 2629 (1992)

17. T. Iwasita-Vielstich in Advances in Electrochemical Science and Engineering, Vol. 1, 127-171. VCH, New York (1990).

18. F. E. Woodard, C. L. Scortichini and C. N. Reilley, J. Electroanal. Chem. 151, 109 (1983). 
19. N. Furuya and S. Kode, Surf. Sci. 220, 18 (1989).

20. K. Yamamoto, D. M. Kolb, R. Kötz and G. Lehmpfuhl, J. Electroanal. Chem. 96, 233 (1979).

21. E. Santos, E. P. M. Leiva, W. Vielstich and U. Linke, $J$. Electroanal. Chem. 227, 199 (1987).
22. A. Rodes, M. A. Zamakhchari, K. El Achi and J. Clavilier, J. Electroanal. Chem. 305, 115 (1991).

23. L. Kristhalik in Advances in Electrochemistry and Electrochemical Engineering, Vol. 7 (Edited by P. Delahay and C. W. Tobias). Wiley and Sons, New York (1970). 